LA-UR- $=98-68$

Title:

LASER MICROMACHINING OF CHEMICALLY ALTERED POLYMERS

$$
\text { CONF-980117-- }
$$

Submitted to:

SPIE Proceedings, Vol. 3274

Los Alamos National Laboratory

Chemical Science and Technology Division

Mailstop J567, Los Alamos, NM 87545

$$
\text { MASTER y }
$$

DISTRIBUTION OF THS DOCUMENT IS UNLMITEO

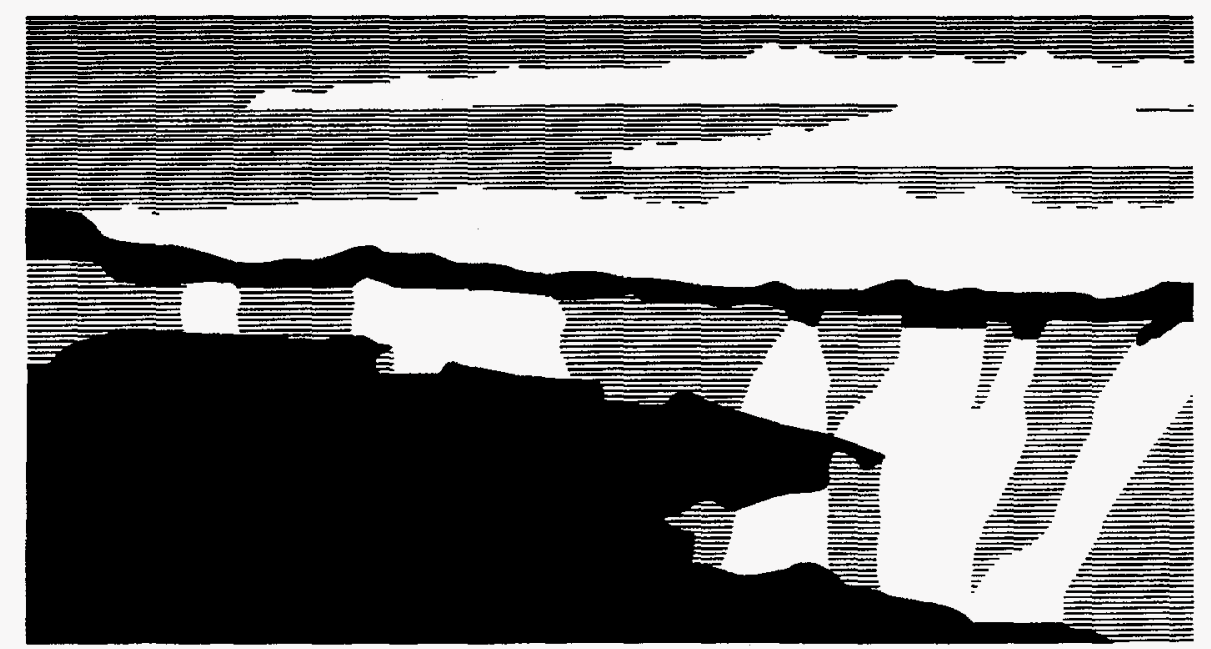

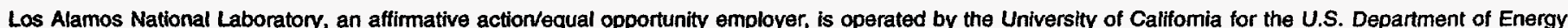

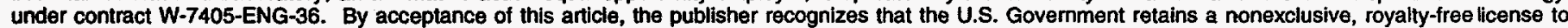
publish or reproduce the published form of this contribution, or to allow others to do so, for U.S. Government purposes. The Los Alamos National Laboratory requests that the publisher identify this article as work performed under the auspices of the U.S. Department of Energy. 


\section{DISCLAIMER}

This report was prepared as an account of work sponsored by an agency of the United States Government. Neither the United States Government nor any agency thereof, nor any of their employees, makes any wartanty, express or implied, or assumes any legal liability or responsibility for the accuracy, completeness, or usefulness of any information, apparatus, product, or process disclosed, or represents that its use would not infringe privately owned rights. Reference herein to any specific commercial product, process, or service by trade name, trademark, manufacturer, or otherwise does not necessarily constitute or imply its endorsement, recommendation, or favoring by the United States Government or any agency thereof. The views and opinions of authors expressed herein do not necessarily state or reflect those of the United States Government or any agency thereof. 


\section{DISCLAIMER}

Portions of this document may be illegible electronic image products. Images are produced from the best available original document. 


\title{
Laser micromachining of chemically altered polymers
}

\author{
Thomas Lippert ${ }^{1}$, \\ $5-4379$
}

Los Alamos National Laboratory, CST 6, MS J 585, Los Alamos, NM 87545,

\begin{abstract}
During the last decade laser processing of polymers has become an important field of applied and fundamental research. One of the most promising proposal, to use laser ablation as dry etching technique in photolithography, has not yet become an industrial application. Many disadvantages of laser ablation, compared to conventional photolithography, are the result of the use of standard polymers. These polymers are designed for totally different applications, but are compared to the highly specialized photoresist. A new approach to laser polymer ablation will be described; the development of polymers, specially designed for high resolution laser ablation. These polymers have photolabile groups in the polymer backbone, which decompose upon laser irradiation or standard polymers are modified for ablation at a specific irradiation wavelength. The absorption maximum can be tailored for specific laser emission lines, e.g. 351,308 and $248 \mathrm{~nm}$ lines of excimer lasers. We will show that with this approach many problems associated with the application of laser ablation for photolithography can be solved. The mechanism of ablation for these photopolymers is photochemical, whereas for most of the standard polymers this mechanism is photothermal. The photochemical decomposition mechanism results in high resolution ablation with no thermal damage at the edges of the etched structures. In addition there are no redeposited ablation products or surface modifications of the polymer after ablation.
\end{abstract}

Keywords: Photopolymer, laser ablation, mechanism, excimer laser, triazenopolymer

\section{INTRODUCTION}

During the last decade, processing of polymers has become an important field of applied and fundamental research [1]. One of the most important fields is laser ablation which is used as an analytical tool for MALDI (matrix assisted laser desorption ionization) [2,3] and LIBS (laser induced breakdown spectroscopy) [4,5] or as a preparative tool for PLD (pulsed laser deposition) [6,7] of synthetic polymer films. The application of high energy UV lasers led to the discovery of a process termed ablative photodecomposition (APD) in 1982 [8,9]. One of the most promising proposals for APD was for its application as a dry etching technique in photolithography. APD promised a higher resolution, due to the use of the shorter laser wavelength as compared to the traditional UV lamp techniques, and a lower number of processing steps. For a 'real' dy etching technique there would be no need for a wet development. This would also eliminate a part of the liquid waste. Until now APD is mainly used for producing via-holes in polyimide (PI) on MCM (multi chip modules) [10] and not as a dy etching technique in photolithography. This is partly due to several disadvantages of APD compared to conventional photolithography. One reason is the comparison of lithography with APD using standard polymers such as PI, PET (polyethylene-terephthalate) or PMMA (poly-methyl-methacrylate) [11-13] which are designed for totally different applications, but are compared to the highly developed and specialized photoresists. For an application of laser ablation in an industrial process, such as the production of TFT-LCD's, new material are needed which exhibit low threshold fluences and ablation rates of about $100 \mathrm{~nm} /$ pules at $100 \mathrm{~mJ} \mathrm{~cm}^{-2}[14,15]$. Other problems of laser ablation are the redeposition of ejected material (debris) and an incomplete ablation at low fluences. In order to overcome these problems we choose to develop special polymers for laser ablation at a specific laser wavelength based on photolabile $-\mathrm{N}=\mathrm{N}-\mathrm{X}$ - groups in the polymer main chain or by modifying a commercial polymer (polycarbonate, PC). As an irradiation source we chose a XeCl excimer laser emitting at $308 \mathrm{~nm}$. This laser wavelength has the following advantages: $\mathrm{HCl}$ as the halogen source is easier to handle than $\mathrm{F}_{2}$ required for the $\mathrm{KrF}$ lasers; high power $\mathrm{XeCl}$ industrial lasers are the most advanced on the market, and the output level is sustained for more than $8 \mathrm{~h}$ of continuous operation; the $308 \mathrm{~nm}$ wavelength is also more forgiving than the deep UV radiation; typical optical materials and coatings have lower absorption and higher damage thresholds at $308 \mathrm{~nm}$ as compared to $248 \mathrm{~nm}$ or even $193 \mathrm{~nm}$. One other important motivation of our approach was the controversy over the mechanism of ablation. It has been suggested that the mechanism is either mainly thermal, photothermal, or photochemical, or a mixture of

\footnotetext{
' Further correspondence information:

T.L.: Email: lippert@lanl@gov: Telephone: 505-665-4379: Fax: 505-665-4817
} 
these [11-13]. From an application standpoint, a photochemical mechanism would be most desirable. Photochemical decomposition would have an intrinsically higher resolution due to the lack of thermal damage to the surrounding area, and the polymer could be designed in a similar way to the photoresists, considering mainly the photochemical properties of various chromophores. In addition, it would be possible to design polymers which decompose mainly to gaseous products. This would delete the problem of redeposited material, the so called debris. The incomplete removal of the polymer requires additional cleaning steps, thus losing one of the big advantages of APD- the lower number of processing steps.

\section{Experimental}

\section{Materials}

The $-\mathrm{N}=\mathrm{N}-\mathrm{X}$ - polymers (general structure shown in scheme 1) were synthesized according to procedures described elsewhere $[16,17]$. Briefly the synthesis is a interfacial polycondensation of a bis-diazonium salt with the corresponding coupling

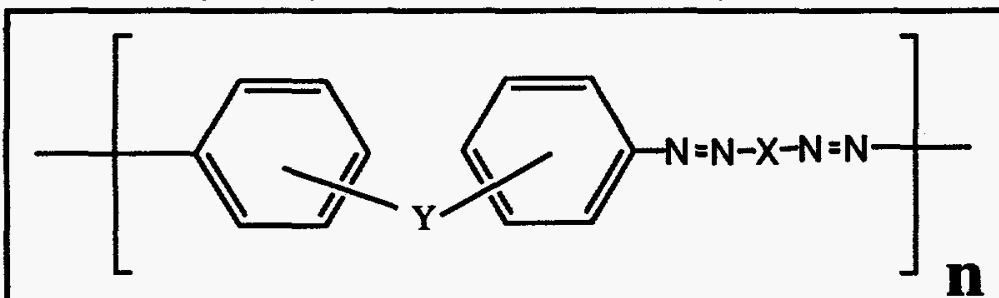

$\mathrm{Y}: \mathrm{O}, \mathrm{CO},-, \mathrm{m}-\mathrm{SO}_{2}, \mathrm{p}-\mathrm{SO}_{2}$

$X: N\left(R_{1}\right)-R_{2}-N\left(R_{1}\right)$ triazeno-

$S\left(R_{1}\right)-R_{2}-S\left(R_{1}\right)$ diazo-sulfido-

$N\left(R_{1}\right)$ pentazadieno-

$\stackrel{O}{\mathrm{P}}-\mathrm{O}-\mathrm{R}_{4} \mathrm{O}-\stackrel{\mathrm{O}}{\mathrm{P}}$
$\stackrel{\mathrm{O} R_{3}}{\mathrm{O} R_{3}}$

Scheme 1: General structure of the $-\mathrm{N}=\mathrm{N}-\mathrm{X}$ - polymers.

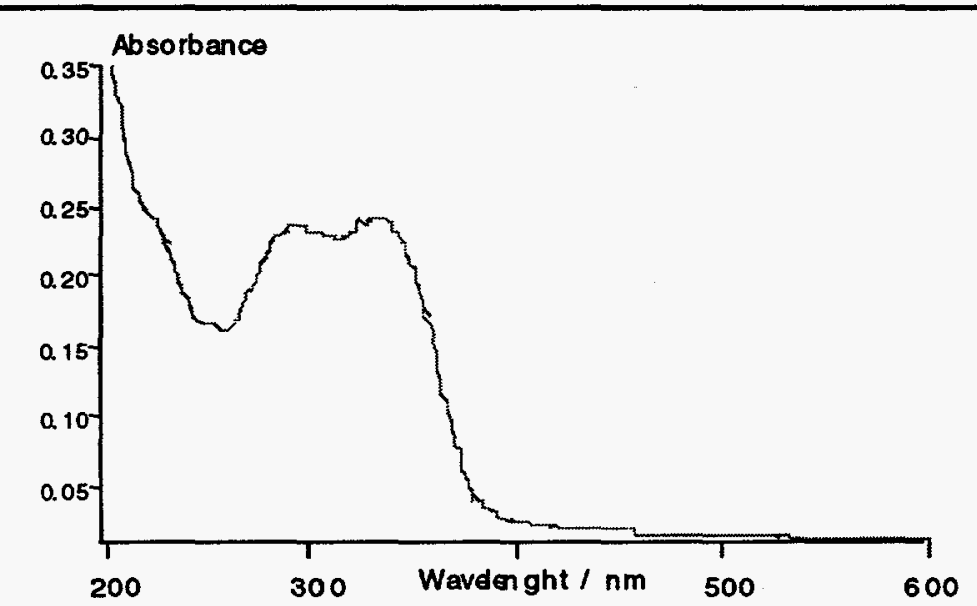

Figure 1: UV-Vis spectra of a triazenopolymer with $(Y=0)$. compound. The absorption maximum of the polymer and other polymer properties can be varied by changing $Y$ and $R / X$. For example, the absorption maximum of the triazeno-polymers can be varied between $290 \mathrm{~nm}$ and $350 \mathrm{~nm}$. A typical UV spectrum of a thin film is shown in Fig. 1.

The modification of a commercial polycarbonate was done in cooperation with BAYER AG [18].

\section{Instrumental}

Ablation rates were determined using a $\mathrm{XeCl}$ excimer laser, a profilometer or an atomic force microscope (AFM). For the studies of the mechanism we also used $\mathrm{XeF}$ (351 nm), $\mathrm{KrF}$ (248 $\mathrm{nm}$ ) various dye lasers and Nd:YAG lasers.

\section{Results and Discussion}

All synthesized $-\mathrm{N}=\mathrm{N}-\mathrm{X}$ - polymers with two $-\mathrm{N}=\mathrm{N}$ - groups per repetition unit exhibit ablation rates which are highly reproducible and linear with pulse number. Maximum ablation rates of up to 3 $\mu \mathrm{m} /$ pulse could be achieved, a value much higher than predicted from the linear absorption coefficients [19]. Possible reasons for this behavior are discussed in later section. With the introduction of the two photolabile groups into each repetition unit of the polymer main chain a well defined decomposition pathway (shown in scheme 2) is followed.

After the homolytic bond scission between the $-\mathrm{N}-\mathrm{X}$ - bond two radicals result. Nitrogen is eliminated on a very fast time scale from the extreme labile azo-radical. The well defined photochemical decomposition pattern and the gaseous products result in clean ablation contours with no redeposited material, as shown in Fig. 2. 


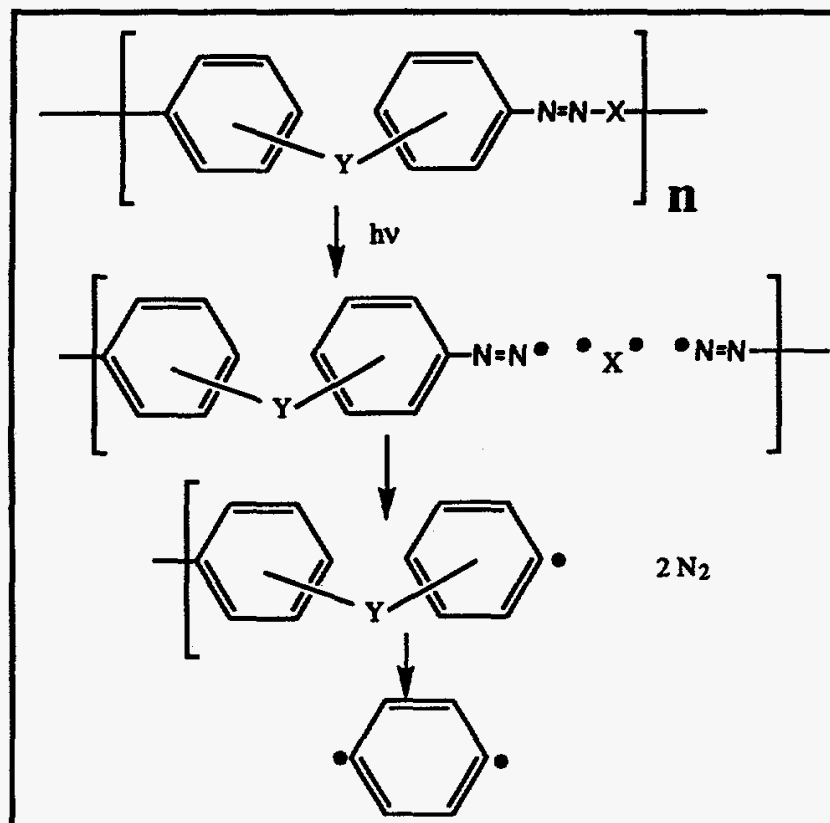

Scheme 2: Photochemical decomposition pathway of the $\mathrm{N}=\mathrm{N}-\mathrm{X}$ - polymers.

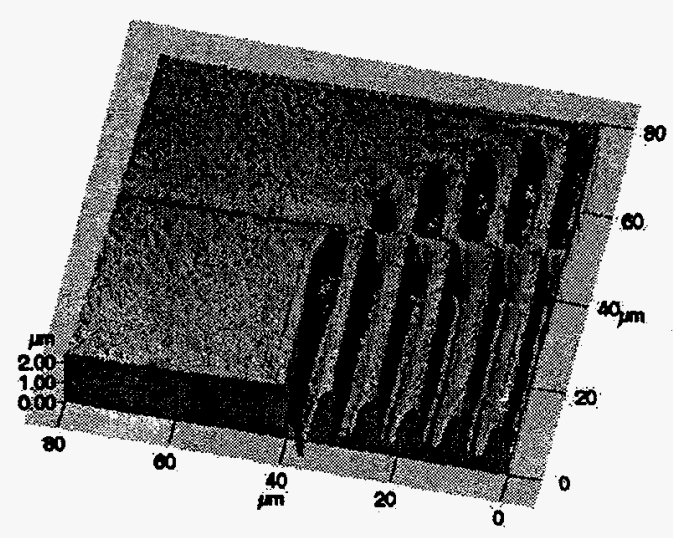

Figure 2: AFM-picture of a triazene polymer (TP 1), ( $\lambda_{\text {irr }}=308 \mathrm{~nm}, \mathrm{~F}=7.5 \mathrm{~J} / \mathrm{cm}^{2}, 1$ pulse ).

Sensitivity tests revealed that some of the polymers with $Y=S-R_{2}-S$ and $N\left(R_{2}\right)$ are two sensitive for laser irradiation or safe handling. The polymers decomposed upon laser irradiation or impact completely. The diazophosphonate polymers were stable during laser irradiation, but showed a high sensitivity to the electron beam of the scanning electron microscope (SEM). The triazeno compounds proofed to be the most stable polymers (storage, $S E M$ ) which combined high ablation rates with a high sensitivity. The threshold fluence, $F_{t b}$, at $308 \mathrm{~nm}$ was $22 \mathrm{~mJ} \mathrm{~cm}^{-2}$ [20] and ablation rates per pulse of $120 \mathrm{~nm}$ at $100 \mathrm{~mJ} \mathrm{~cm}^{-2}$ and $130 \mathrm{~nm}$ at $140 \mathrm{~mJ} \mathrm{~cm}^{-2}$ did result at $308 \mathrm{~nm}$ for a polymer with $\mathrm{Y}=0$. Using a different polymer with $\mathrm{Y}=\mathrm{m}-\mathrm{SO}_{2}$ and an irradiation wavelength of $351 \mathrm{~nm}$ an ablation rate of $140 \mathrm{~nm}$ at $60 \mathrm{~mJ}$ $\mathrm{cm}^{-2}$ could be achieved. Tests whether a complete removal of the polymer is possible with fluences as low as $100 \mathrm{~mJ} \mathrm{~cm}^{-2}$ suggested that this is possible with a "clean" polymer. The achievable resolution is close to the diffraction limit, suggesting a possible application in fields where the necessary resolution is $\geq 0.5 \mu \mathrm{m}$.

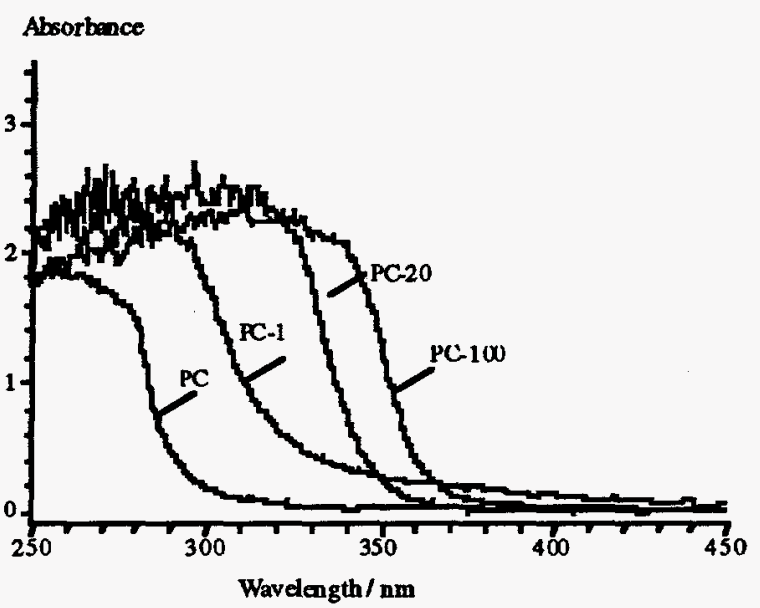

Figure 3: UV-Vis spectra of various modified PC's. Numbers are corresponding to the \% of the incorporated ester. (solid films, thickness: $\approx 200 \mu \mathrm{m}$ ).
In an alternative approach we modified an existing industrial polymer, in detail polycarbonate (Makrolon ${ }^{\mathrm{TM}}$ ), for ablation at $308 \mathrm{~nm}$. Polycarbonates are well soluble in standard solvents, have very good mechanical and thermal properties and high quality films can be obtained by various techniques. The modification of the polycarbonate (PC) was realized by incorporating of aromatic ester groups into the polymer chain. By varying the amount of the incorporated ester group the absorption edge of the PC could be shifted to longer wavelengths, as shown in Fig. 3. By incorporating an ester group into the polymer chain the ablation quality of the polycarbonates at $308 \mathrm{~nm}$ could be improved drastically. In Fig. 4a the ablation contour of a PC film without ester groups is shown. The edge and bottom of the ablation crater is rough with redeposited or ejected molten material surrounding the crater. In case of the incorporated ester group, shown in Fig $4 \mathrm{~b}$ clean ablation contours with no detectable redeposited material are found. An example of the achievable resolution is shown in Fig. 5. Maximum ablation rates of up to $2 \mu \mathrm{m} /$ pulse were realized. The polymer could also be ablated with fluences below $150 \mathrm{~mJ} \mathrm{~cm}^{-2}$ but a complete removal of the material was not possible. The remaining layer consists most probably of various carbon species. 

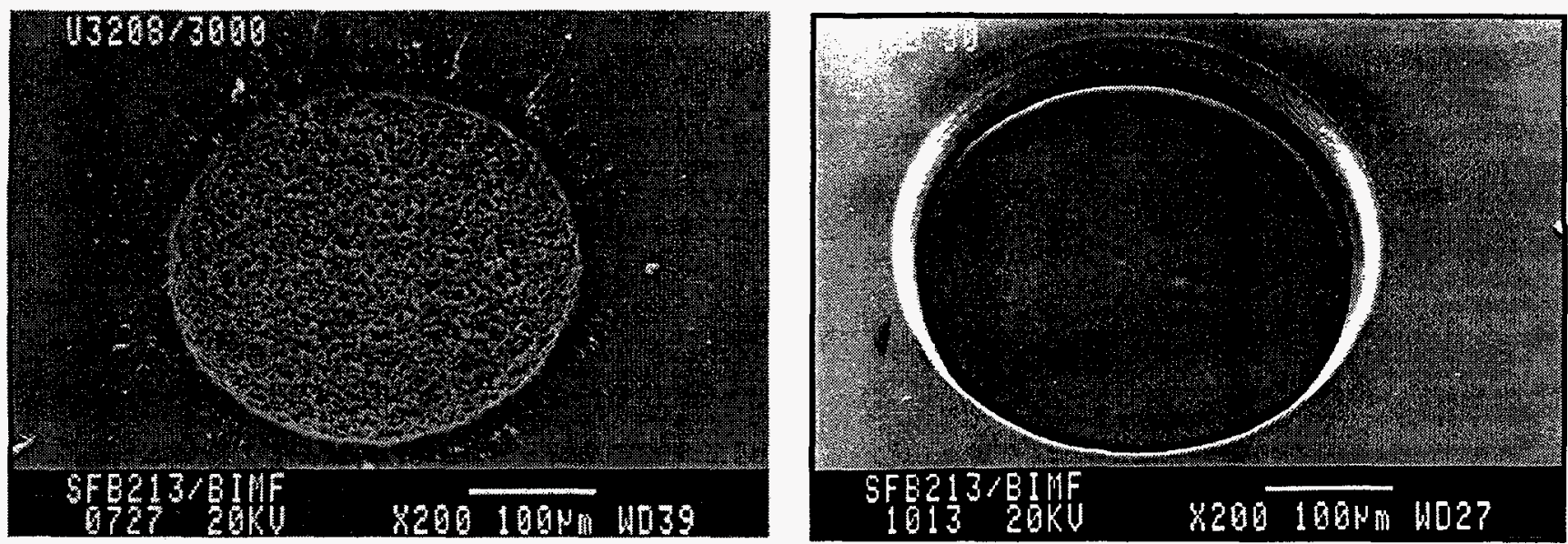

Figure 4: SEM-picture of an ablation crater in a) poly-carbonate film PC-0 (=PC) $\left(\lambda_{\text {irr }}=308 \mathrm{~nm}, 15\right.$ pulses, $\left.7.66 \mathrm{~J} / \mathrm{cm}^{2}\right)$ (left) and b) polycarbonate film with $30 \%$ ester content (PC-30) $\left(\lambda_{i \mathrm{~m}}=308 \mathrm{~nm}, 15\right.$ pulses, $\left.18.45 \mathrm{~J} / \mathrm{cm}^{2}\right)$ (right).

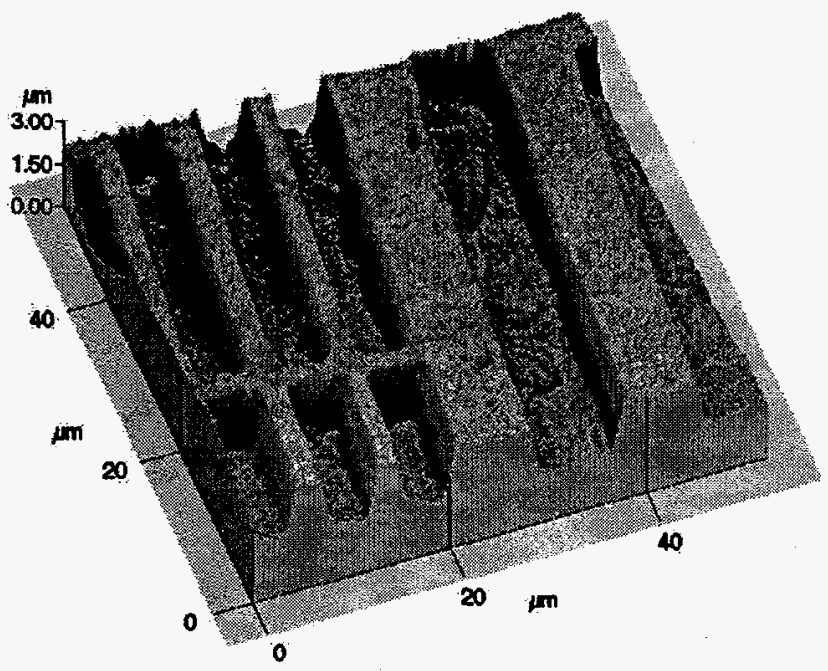

Figure 5: AFM-picture of the polycarbonate with $100 \%$ of ester content. $\left(\lambda_{\text {irr }}=308 \mathrm{~nm}, F=7.5 \mathrm{~J} / \mathrm{cm}^{2}, 1\right.$ pulse ): no redeposited debris on the surface.

\section{Mechanism}

To study whether our concept of incorporating photolabile groups into the polymer main chain results in a photochemical or dominating photochemical ablation mechanism we used various analytical and time-resolved spectroscopic techniques on the most promising $-\mathrm{N}=\mathrm{N}-\mathrm{X}$ polymers. Using surface analytical techniques we could show that the chemical composition of the polymer did not change after irradiation at $308 \mathrm{~nm}$ (contact angle and XPS). For irradiation at $248 \mathrm{~nm}$ surface carbonization could be detected [21]. Time resolved transmission studies at the irradiation wavelength revealed an increased transmission of the laser pulse, suggesting a decomposition of the polymer during the pulse [20]. This could be confirmed with time resolved surface interferometry, which proofed that etching of the polymer during the laser pulse (starting and ending with the laser pulse) takes place at modest fluences $\left(>200 \mathrm{~mJ} \mathrm{~cm} \mathrm{~cm}^{-2}\right)$ [22]. At lower fluences an additional delayed etching was detected, suggesting a thermal part in the ablation mechanism. Using ns-imaging above the polymer surface the absence of larger solid abalation products could be confirmed. The resulting shock wave was analyzed using a microexplosion model with incorporated "explosive energy" of the polymer decomposition [23]. The products of ablation were studied using time-of-flight mass spectrometry (TOF-MS) $[24,25]$. Only products compatible with the above shown (scheme 2) photochemical decomposition mechanism were found. The TOF curves of the two main products, $\mathrm{N}_{2}$ and phenyl, were analyzed in more detail. Gaussian energy distributions yielded an average kinetic energy of $0.8 \mathrm{eV}$ for $\mathrm{N}_{2}$ and $\approx 4 \mathrm{eV}$ for the phenyl fragment. These energies are too high for a thermal decomposition mechanism, but might be explained by a photochemical mechanism with 'explosive' ejection of the fragments.

\section{Conclusion}

The existing data show that laser ablation can be used as a "true" high resolution dry etching technique, if tailored polymers are used. The combination of photolabile energetic groups in the polymer main chain, which decompose to gaseous products, 
results in clean etching contours with no surface contamination by ablation products. The specially designed triazenopolymers reveal some unique features: wavelength selective surface modification and etching. The data analysis also shows that the mechanism is mainly dominated by photochemical features (clean etching, no surface modification, etching starts and ends with the laser pulse), but that additional parameters, such as the decomposition energy also influence the mechanism. By chemically altering a 'standard' industrial polymer, polycarbonate, it was possible to achieve high resolution ablation with no debris contaminating the polymer surface after irradiation.

\section{ACKNOWLEDGEMENTS}

T. L. expresses his gratitude to Los Alamos National Laboratory for a research fellowships and sincere thanks to T. Kunz, A. Wokaun, H. Fukumura, H. Furutani, H. Masuhara, T. Dickinson, S. Langford and A. Yabe for various contributions.

\section{REFERENCES}

1. Fouassier, J.-P.; Rabek, J. F. (Eds.). Lasers in polymer science and technology: applications, Vol. 1-IV, CRC Press, Boca Raton 1990.

2. Williams, J. B., Gesev, A. I., Hercules, D. M. Macromolecules 30, 3781 (1997).

3. Allwood, D. A., Dyer, P. E., Dreyfus, R. W., Perera, I. K. Appl. Surf. Sci. 110, 616 (1997).

4. Multari, R. A., Foster, L. E. Cremers, D. A., Ferris, M. J. Appl. Spectrosc. 50, 1483 (1996).

5. Vadillo, J. M., Palanco, S., Romero, M. D., Laserna, J. J. Fres. J. Anal. Chem. 355, 909 (1996).

6. Blanchet, G. B. Chemtech, June 31 (1996)

7. Jiang, W., Norton, M. G., Tsung, L., Dickinson, J. T. J. Mater. Res. 10, 1038 (1995).

8. Kawamura, Y., Toyoda, K., Namba, S. Appl. Phys. Lett. 40, 374 (1982)

9. Srinivasan, R., Mayne-Banton, V. Appl. Phys. Lett. 41, 578 (1982).

10. Patel, R. S., Wassick, T. A.. In: Dubowski, J. J. (Editor), laser applications in microelctronic and manufacturing II, Page 217, proc. SPIE Vol 2991, Bellingham (1997).

11. Dyer, P. E.. In: Boyd, I. W., Jackman, R. B. (Editors), photochemical processing of materials. Page 359, Academic Press, London 1992.

12. Lazare, S., Granier, V. Laser Chem. 10, 25 (1989).

13. Srinivasan, R., Braren, B. Chem. Rev. 89, 1303 (1989).

14. Suzuki, K., Matsuda, M., Ogino, T., Hayashi, N., Terabayashi, T., Amemiya, K.. In: Dyer. P. E., Shields, H. (Editors),excimer lasers optics and applications, Page 98, proc. SPIE Vol 2992, Bellingham 1997.

15. Hayashi, N., Suzuki, K., Matsuda, M., Ogino, T.,Tomita, Y.. In: Dyer. P. E., Shields, H. (Editors), excimer lasers optics and applications, Page 129, proc. SPIE Vol 2992, Bellingham 1997.

16. Stebani, J., Nuyken, O., Lippert, T., Wokaun, A. Makromol Chem. Rapid Commun. 206, 97 (1993).

17. Stebani, J., Nuyken, O., Lippert, T., Wokaun, A., Stasko, A. Makromol Chem. Phys. 196, 739 (1995).

18. Stebani, J., Lippert, T., Kunz, T., Wokaun, A. European Patent No. $96116472.0-2115$ (1996).

19. Lippert, T., Stebani, J., Ihlemann, J., Nuyken, O., Wokaun, A. J. Phys. Chem. 97, 12296 (1993).

20. Lippert, T., Bennett, L. S., Nakamura, T., Niino, H., Ouchi, A., Yabe, A. Appl. Phys. A 63, 257 (1996).

21. Lippert, T., Nakamura, T., Nino, H., Yabe, A. Macromolecules, 29, 6301 (1996).

22. Furutani, H., Fukumura, H., Masuhara, H., Lippert, T., Yabe, A. J. Phys. Chem. 101, 5742 (1997).

23. Bennett, L. S., Lippert ,T., Furutani, H., Fukumura, H., Masuhara, H. Appl. Phys. A 63, 327 (1996).

24. Lippert, T., Bennett, L. S., Kunz, T., Hahn, C., Wokaun, A., Furutani, H., Fukumura, H., Masuhara, Yabe, A.. In: Dyer. P. E., Shields, H. (Editors),excimer lasers optics and applications, Page 135, proc. SPIE Vol 2992, Bellingham 1997.

25. Lippert, T., Dickinson, J. T., Langford, S., A., Furutani, H., Fukumura, H., Masuhara, Kunz, T., Wokaun, A., Appl. Surf. Sci., 1998, in press. 